\title{
典型喀斯特流域旱雨季交替下溶解硅的输送特征
}

\author{
郝 卓 $^{1}$, 高 扬 ${ }^{2, *}$, 张晴雯 ${ }^{1}$, 熊佰炼 $^{3}$
}

1 中国农业科学院农业环境与可持续发展研究所,农业清洁流域团队,北京 100081

2 中国科学院地理科学与资源研究所,生态系统网络观测与模拟重点实验室,北京 100101

3 遵义师范学院资源与环境学院, 遵义 563006

\begin{abstract}
摘要: 河流溶解硅 $(\mathrm{DSi})$ 作为营养物质对维持陆地、河流及海洋生态系统稳定性起到至关重要的作用。选取贵州典型喀斯特流 域为研究对象,通过对 DSi 湿沉降过程,基流过程及降雨径流过程的动态变化进行全年监测分析,探讨 DSi 在旱雨季交替下的 输送特征及河流 DSi 浓度变化引起的环境效应。结果表明: 1 湿沉降过程降雨量越大, DSi 浓度越小, 河流 DSi 浓度变化有明显 的旱、雨季特征, 雨季 DSi 浓度较高, 旱季较低, 地表水径流量及 DSi 浓度对降雨径流过程的响应比地下水明显。(2)DSi 沉降通 量及输出通量呈明显的旱、雨季差异, 雨季 DSi 湿沉降通量占全年的 $69.5 \%$,地表水雨季 DSi 输出负荷占全年的 $98.1 \%$, 地下水 占 $51.4 \%$ 。(3流域硅酸盐岩风化过程不强烈, 主要受到碳酸盐岩及蒸发岩控制。流域 DSi 浓度受人为水库影响明显, 经过水库 后河流中 DSi 浓度旱季下降 $29.0 \%$ 、雨季下降 $70.9 \%$ 。研究为全面认识硅在陆地生态系统中的生物地球化学循环提供科学 依据。
\end{abstract}

关键词 : 喀斯特流域;溶解硅;旱雨季; 岩石风化;溶解硅通量

\section{Characteristics of dissolved silicon transport in typical karst watershed in alternating wet and dry season}

\footnotetext{
HAO Zhuo ${ }^{1}$, GAO Yang ${ }^{2, *}$, ZHANG Qingwen ${ }^{1}$, XIONG Bailian ${ }^{3}$

1 Agricultural Clean Watershed Research Group, Institute of Environment and Sustainable Development in Agriculture, Chinese Academy of Agricultural Sciences, Beijing 100081, China

2 Key Laboratory of Ecosystem Network Observation and Modeling, Institute of Geographic Sciences and Natural Resources Research, Chinese Academy of Sciences, Beijing 100101, China

3 Department of Resources and Environment, Zunyi Normal College, Zunyi 563006, China
}

\begin{abstract}
Dissolved silicon (DSi) in natural waters plays important roles in sustaining continent, riverine and ocean ecosystems. It is a necessary nutrient for the growth and reproduction of aquatic plants and phytoplankton, especially diatoms. The composition of dissolved silicon in river systems is complex and depends on physical, chemical, and biological processes that occur in drainage basins and rivers. In this study, a typical karst watershed located in Guizhou Province, Southwest China was selected as the study area to reveal the characteristics of DSi transport and discuss seriously environmental effects on the variation of DSi concentration. The objects of this research were to monitor the dynamic characteristics of dissolved silicon in wet deposition, rainfall-runoff processes and baseflow process in the dry and wet seasons during the whole year and to discuss about serious environmental effects on the variation of DSi concentration. Results showed that (1) The greater the rainfall, the smaller the DSi concentration during the wet deposition. DSi
\end{abstract}

基金项目: 国家自然科学面上基金项目 (41922003,41871080,41977072)

收稿日期: 2020-12-08; 网络出版日期 : 2021-08-04

* 通讯作者 Corresponding author.E-mail: gaoyang@ igsnrr.ac.cn 
concentration in the wet season was higher than that in the dry season. DSi concentration and discharge in surface water were more easily responded by rainfall-runoff process than in groundwater. (2) The deposition flux and export flux of DSi showed evident differences in the wet and dry seasons. DSi deposition flux in the wet season accounted for 69.5\%, and export load of surface water and groundwater accounted for $98.1 \%$ and $51.4 \%$ of the whole year, respectively. (3) The study area had a slow weathering rate of silicate minerals which was mainly controlled by carbonates and evaporite rates. DSi concentration was significantly affected by man-made reservoir as the results showed that the DSi concentration dropped by $29 \%$ and $70 \%$ in the dry and wet seasons, respectively. The study is conducive to a more comprehensive understanding of the silicon biogeochemical cycle in terrestrial ecosystems. In future studies, long-term studies on the effects of agricultural activities and land use patterns on the supply of nutrients in the watershed are needed to predict the change of phytoplankton community with the dynamic change of DSi concentration from a long-term perspective. In addition to DSi monitoring, BSi monitoring should be added to further study the silicon cycling process and related environmental effects in terrestrial ecosystems.

Key Words : karst watershed; dissolved silicon; dry and wet seasons; rock weathering; dissolved silicon flux

中国西南地区处于喀斯特关键带, 是世界三大喀斯特分布区之一, 以贵州为中心的喀斯特集中分布区岩 溶发育强烈, 碳酸盐岩及硅酸盐岩矿物丰富 ${ }^{[1-2]}$ 。喀斯特水系具有独特的地表地下二元结构, 降雨人渗后形 成降雨-地表-地下 “三水” 承载的生源要素迁移转化过程复杂 ${ }^{[2-4]}$ 。水流在溶洞, 裂隙及管道中流动发生强烈 的水力联系, 水流通过土壤孔隙, 不仅与土壤直接接触, 还与岩石表面充分接触, 使得水体中的岩石溶解物质 丰富 ${ }^{[5-6]}$ 。硅 $(\mathrm{Si})$ 是一种普遍存在的元素, 并且与其他元素的生物地球化学循环具有复杂的相互作用 ${ }^{[7-9]}$ 。 溶解硅 $(\mathrm{DSi})$ 是淡水和海洋生态系统的重要营养物质, 主要来自于土壤及表层岩石的化学风化作用。河流中 的硅主要以径流输人的土壤、颗粒态硅 $(\mathrm{PSi})$ 以及生物硅 $(\mathrm{BSi})$ 的形式存在, PSi 和 BSi 在水体的迁移过程中, 部分沉积至河底, 部分分解释放为 DSi 参与河流的 $\mathrm{Si}$ 循环过程 ${ }^{[7,10-11]}$ 。河流作为连接陆地生态系统及海洋生 态系统的重要纽带, 每年从河流输送到海洋的溶解性及颗粒状生源要素占陆地到海洋运输量的 $90 \%{ }^{[12]}$ 。全 球 DSi 预算报告指出每年以全球河流系统进人海洋约为 $370 \mathrm{Mt} \mathrm{SiO}_{2}{ }^{[13-14]}$ 。因此, 河流承载着 DSi 的外源输人 及迁移过程 ${ }^{[1]}$ 。

随着河流富营养化状态日益加重, 人为筑坝,生态破坏导致水文情势的改变,引发藻类加速生长,使得河 流 DSi 浓度显著下降, 对硅的地球化学循环平衡产生严重的影响, 对河口及海洋引发不良的环境效应 ${ }^{[11]}$ 。目 前, 关于水体 DSi 的研究逐渐成为热点, 但大多集中在河流人海口或流动性差的水库探讨 $\mathrm{Si}$ 的生物地球化学 循环过程。我国喀斯特面积较大, 岩溶发育强烈, 但至今对于喀斯特地区 DSi 通量的研究鲜有报道 ${ }^{[15]}$ 。本文 选取贵州典型喀斯特流域, 在岩溶流域尺度上对降雨、地表水及地下水 DSi 浓度进行了为期一年的监测, 分析 旱、雨季交替下水体 DSi 的运移通量变化特征, 探讨喀斯特流域水体 DSi 迁移的驱动机制及岩石风化作用对 DSi 浓度的影响, 并结合当地人为活动评估其环境效应, 以期为喀斯特地区河流营养盐输送及生态恢复提供 科学依据。

\section{1 材料与方法}

\section{1 研究区概况}

后寨河流域位于贵州省安顺市普定县 $\left(26^{\circ} 17^{\prime} 05.30^{\prime \prime} \mathrm{N}, 105^{\circ} 39^{\prime} 21.44^{\prime \prime} \mathrm{E}\right)$, 流域面积为 $80.65 \mathrm{~km}^{2}$, 海拔在 1218-1585 m 之间。研究区属亚热带季风气候, 春季干燥, 夏季湿润, 5-8 月集中降雨, 年平均降雨量为 $1314.6 \mathrm{~mm}$, 年平均温度为 $15.1^{\circ} \mathrm{C}$ 。流域内后寨河河床渗漏严重, 河流明暗交替, 后寨地下河水系相当发育, 是 普定县重要的供水水源 ${ }^{[4]}$ 。后寨河流域内基岩类型主要为三叠系中统关岭组的石灰岩和白云岩, 砂页岩较 少, 土壤类型为黄壤、石灰土和水稻土, 流域内土壤质量差, 土层浅薄且不连续 ${ }^{[16-17]}$ 。 


\section{2 采样方法}

常规采样点: 分别布置 10 个采样点, 1 号点为后寨河总出口 (包含地表水 No. $1 \mathrm{~S}$ 和地下水 No.1G 及交汇 点 No.1M)。No. $1 \mathrm{G}$ 为流域地下水出口处, 在 No.1G 点处地下水涌上地面,直接人工采集样品。每月固定时间 人工采集 2 次河水样品, 采集 $100 \mathrm{~mL}$ 河水装人聚乙烯瓶(图 1)。

降雨过程样品: 在 1 号点采集地表水 (No.1S) 及地下水 (No.1G) 收集 3 场完整降雨过程 (3 场次降雨事 件) 作为降雨驱动下的径流过程样品 (降雨径流过程) 共计 12 个, 分为雨前, 雨中, 雨后进行采集。其中雨前 采样 2 次,雨中采样 8 次 (每次间隔 20-30 min), 雨后采样 2 次。采集 $100 \mathrm{~mL}$ 河水装入聚乙烯瓶。

雨水采集: 在试验区屋顶安装雨量计,每次降雨后, 人工采集。所有样品采集后放置于培养箱中 $4^{\circ} \mathrm{C}$ 冷藏 保存并送至实验室试验及时分析。

在后寨河流域总出口处设置用于观测流量的导流渠和三角堰利用 HOBO 水位记录仪( U20 型, 美国 ONET 公司) 每隔 5 min 监测获得连续的水位数据, 根据堰流公式计算流量值。

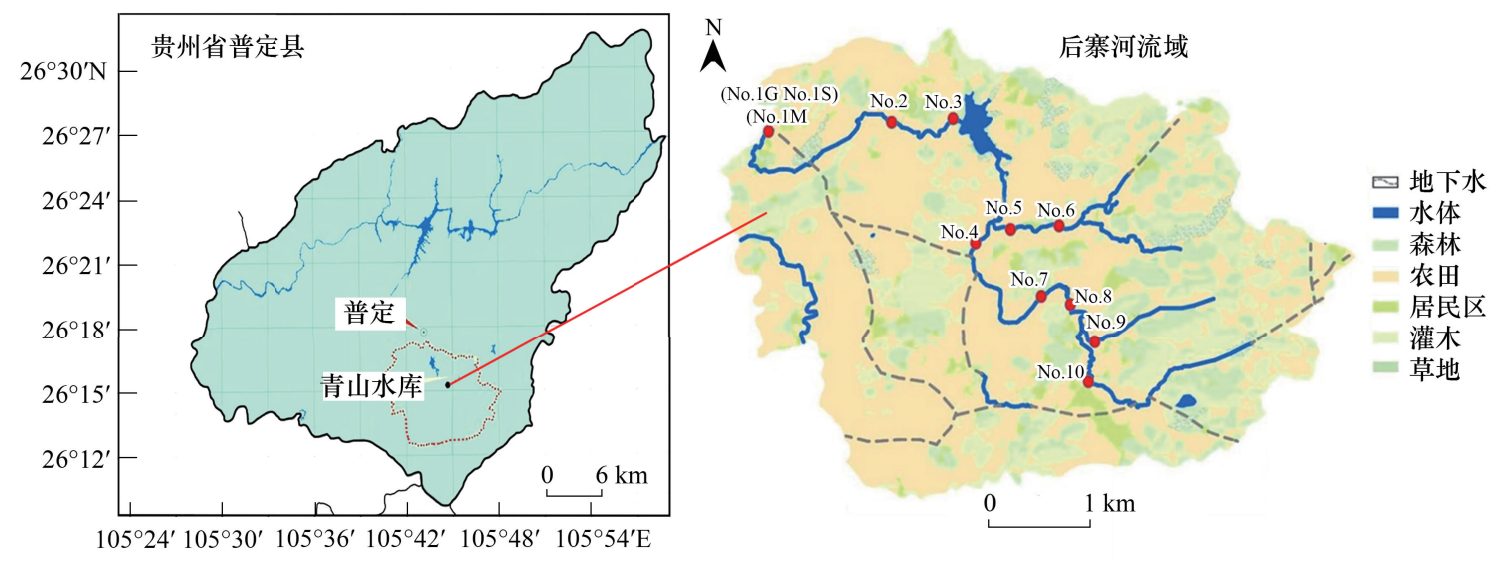

图 1 贵州普定后寨河流域采样点分布图

Fig.1 The location of Puding in Guizhou and the sampling points in Houzhai River Basin.

NO.1G: 1 号地下水采样点; NO.1S:1 号地表水采样点; NO.1 M: 1 号地表与地下水汇合采样点

\section{3 样品分析}

水样经 $0.45 \mu \mathrm{m}$ 有机微孔滤膜过滤后, 利用电感耦合等离子体发射光谱仪( ICP-OES) ( Thermo Fisher Scientific, Darmstadt, Hesse, 德国) 测定 DSi, $\mathrm{Na}^{+}, \mathrm{K}^{+}, \mathrm{Ca}^{2+}, \mathrm{Mg}^{2+}$ 浓度。通过离子色谱仪 (美国 Thermo Scientific Aquion IC) 测定 $\mathrm{Cl}^{-}$和 $\mathrm{SO}_{4}^{2-}$ 含量。使用 Ultrameter II pH 计 (美国加利福尼亚州卡尔斯巴德的 Myron L 公司) 测定 $\mathrm{pH}$ 值。

1.4 数据分析

1.4.1 通量计算方法 ${ }^{[18-19]}$

$$
F=\sum\left(\frac{p \times c}{100}\right)
$$

式中, $F$ 代表沉降通量 $\left(\mathrm{kg} / \mathrm{hm}^{2}\right), p$ 代表各场雨的降雨量 $(\mathrm{mm}), c$ 代表雨水中各离子的浓度 $(\mathrm{mg} / \mathrm{L})$ 。

$\mathbf{1 . 4 . 2}$ 污染物负荷计算方法 ${ }^{[20]}$ :

$$
y_{j}=\int_{0}^{t} c_{t}(t) \times q_{t}(t) d t \approx \sum_{i=1}^{n-1} C_{i} Q_{i} \Delta t_{i}=\sum_{i=1}^{n-1} \Delta t \frac{c_{i}+c_{i+1}}{2} \times \frac{q_{i}+q_{i+1}}{2}
$$

式中, $y_{j}$ 为第 $j$ 种污染物的排放负荷 $(\mathrm{g}) ; c_{t}$ 为 $t$ 时刻径流中第 $j$ 种污染物的浓度 $(\mathrm{mg} / \mathrm{L}) ; q_{t}$ 为 $t$ 时刻的流量 $\left(\mathrm{m}^{3} / \mathrm{s}\right) ; c_{i}$ 为第 $\mathrm{j}$ 种污染物在样本 $i$ 监测时的浓度 $(\mathrm{mg} / \mathrm{L}) ; q_{i}$ 为样本 $i$ 在监测时的流量 $\left(\mathrm{m}^{3} / \mathrm{s}\right) ; x$ 为径流量 $\left(\mathrm{m}^{3}\right) ; \Delta t$ 为样本 $i$ 和 $i+1$ 的时间间隔 $(\mathrm{s})$ 。 


\section{2 结果与分析}

2.1 喀斯特流域内大气湿沉降溶解硅 (DSi) 变化特征

本研究在 2017 年 4-9 月共收集 19 场降雨,图 2 为次降雨 DSi 浓度及降雨量变化规律。如图 2 所示, 其 中小雨 $(0-10 \mathrm{~mm}) 11$ 场、中雨 $(10-30 \mathrm{~mm}) 5$ 场及暴雨 $(>50 \mathrm{~mm}$ ) 3 场, 降雨量峰值 $89 \mathrm{~mm}$ 出现在 2017 年 6 月 12 日, 且中雨及暴雨主要集中在夏季 $(6-8$ 月)。DSi 湿沉降浓度变化范围为 $0.22-1.35 \mathrm{mg} / \mathrm{L}$ 。通过与降 雨量加权平均浓度计算得到小雨过程 DSi 平均浓度为 $0.78 \mathrm{mg} / \mathrm{L}$, 中雨过程 DSi 平均浓度为 $0.43 \mathrm{mg} / \mathrm{L}$ 及暴雨 过程 DSi 平均浓度为 $0.34 \mathrm{mg} / \mathrm{L}$, 说明降雨稀释作用明显。降雨量大对大气中污染物的冲刷作用较强, 导致雨 水中 DSi 的浓度较低。但降雨历时长和降雨强度高直接导致 DSi 的沉降通量增加, 3 场暴雨、5 场中雨、11 场 小雨的 DSi 输人通量分别为 $0.64 、 0.46 、 0.26 \mathrm{~kg} / \mathrm{hm}^{2}$ 。

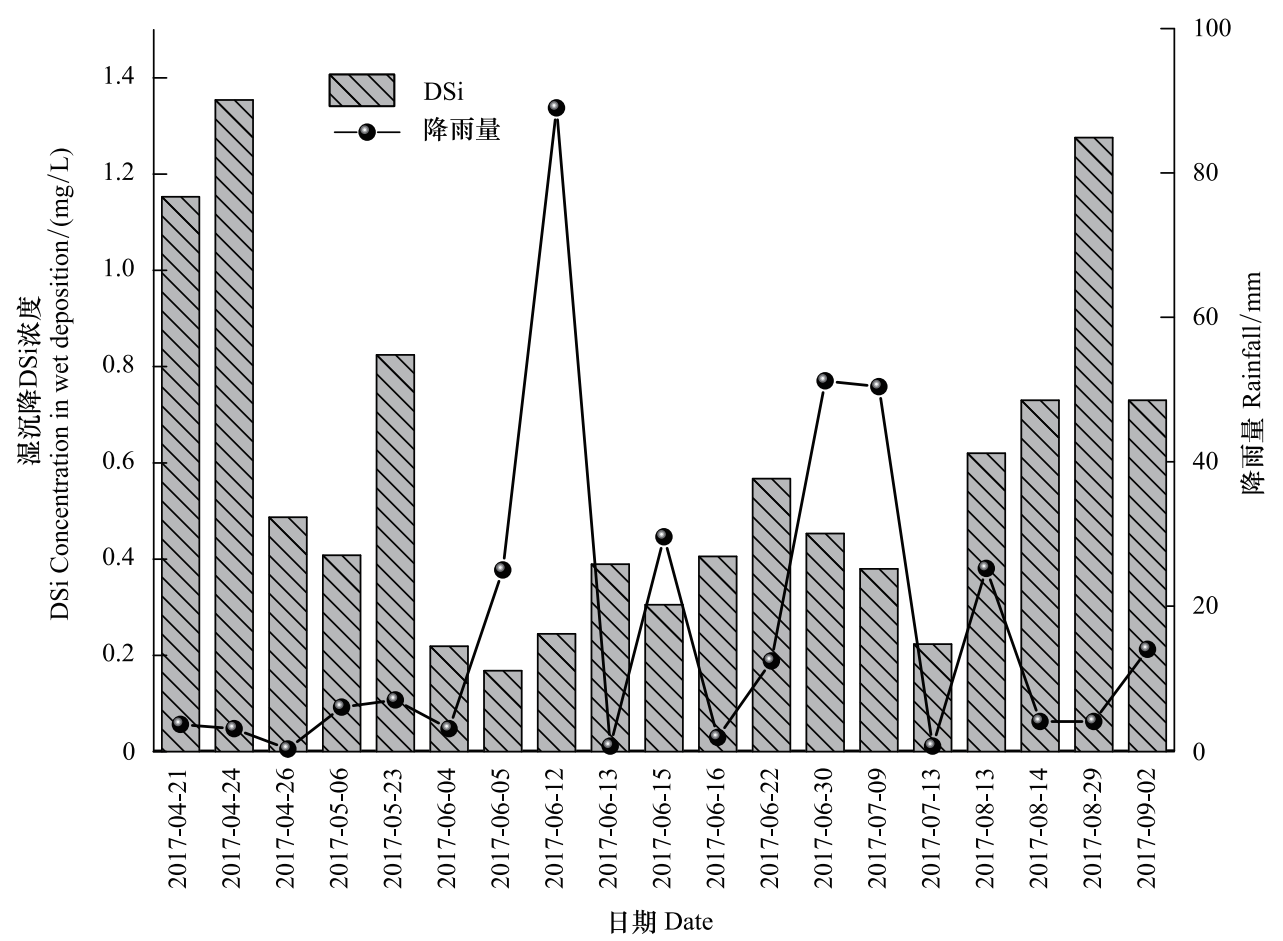

图 2 湿沉降溶解硅浓度变化及降雨量

Fig.2 Variation of dissolved silicon (DSi) concentration and rainfall in wet deposition

\section{2 旱雨季交替下后寨河水体 DSi 浓度变化特征}

本研究根据当地亚热带气候特点, 将 2017 年 1-4 月划分为早季, 5-8 月为雨季, $9-12$ 月为旱季, 图 3 为后寨河流域水体各采样点 DSi 浓度变化特征。如图 3 所示, 后寨河在旱季出现了断流的特征, 在 2 号及 9 号采样点完全断流, 在 4 号、5 号、10 号个别月份也出现断流的情况。1 号采用的地下水浓度明显高于地表 水,且浓度月变化较小, 1 号地表水旱季 ( 1 -4 月) 浓度为 $(1.14 \pm 0.26) \mathrm{mg} / \mathrm{L}$, 地下水平均浓度为 $(3.89 \pm 0.33)$ $\mathrm{mg} / \mathrm{L} 。 1$ 月份水体 DSi 浓度相对较高, 浓度变化范围为 $1.20-5.72 \mathrm{mg} / \mathrm{L}$, 平均值为 $(4.14 \pm 2.00) \mathrm{mg} / \mathrm{L}$, 各采样 点 DSi 浓度起伏较大。2 月水体 DSi 平均浓度最低为 $(2.48 \pm 1.34) \mathrm{mg} / \mathrm{L}$ 。在雨季, $6-8$ 月后寨河水量充足, 这 与雨季降水频繁有直接的关系, 说明后寨河为季节性河流 (图 3)。如图 3 所示, 5 月各采样点浓度最低, 平均 浓度为 $(3.62 \pm 1.98) \mathrm{mg} / \mathrm{L} 。 6-8$ 月 DSi 浓度差异不大, 处于全年较高水平, 平均浓度分别为 $(6.55 \pm 1.29) \mathrm{mg} /$ $\mathrm{L},(6.73 \pm 1.57) \mathrm{mg} / \mathrm{L},(6.83 \pm 2.57) \mathrm{mg} / \mathrm{L}$ 。在 $9-12$ 月份的旱季, 从 10 月份开始出现断流, 各采样点浓度变化 规律与 1-4 月的旱季基本相同。综合图 3 可知, 无论旱、雨季各月份均为 3 号采样点 DSi 浓度最低, 浓度最 低值为 $0.59 \mathrm{mg} / \mathrm{L}$, 平均浓度为 $(0.66 \pm 0.36) \mathrm{mg} / \mathrm{L} 。 3$ 号采样点处于青山水库的出口处, 经过水库的沉积作用 
可能导致出口处水体中 DSi 浓度下降。另外, 雨季后寨河水体 DSi 浓度明显高于旱季, 说明降雨过程中对土 壤淋溶作用强烈,且地表水地下水交换过程迅速, 导致水体中 DSi 浓度升高明显。

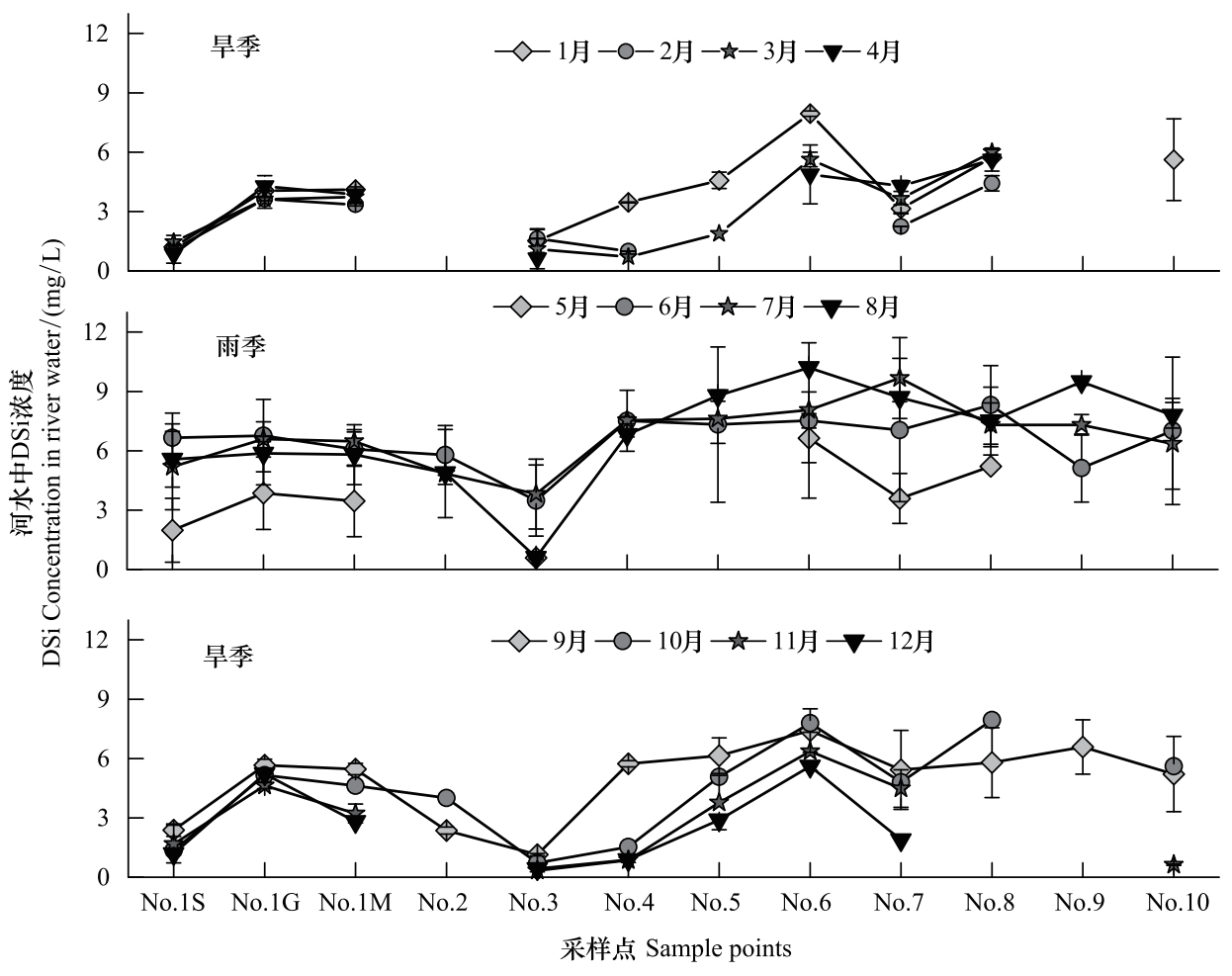

图 3 后寨河流域内水体 $\mathrm{DSi}$ 浓度月变化

Fig.3 Monthly variation of DSi concentration in Houzhai River Basin

2.3 次降雨事件流域地表水径流 DSi 动态变化特征

在雨季, 由于降雨过程对水体 DSi 浓度影响较大, 本研究于 2017 年 8 月在后寨河 1 号采样点地表水及地 下水出口处分别收集 3 场完整的降雨径流过程分析 DSi 动态变化特征。图 4 为地表水 DSi 浓度,降雨过程径 流量及水体 $\mathrm{pH}$ 值变化。如图 4 所示, 2017 年 8 月 25 日 (小雨 $6.4 \mathrm{~mm}$ ) 降雨径流过程 DSi 浓度呈现雨中浓度 降低, 雨前及雨后较高, 浓度变化范围为 $2.39-3.15 \mathrm{mg} / \mathrm{L}, 8$ 月 27 日 (中雨 $13.4 \mathrm{~mm}$ ) DSi 浓度波动范围与其 他两场降雨相比波动范围最大 $2.32-3.76 \mathrm{mg} / \mathrm{L} 。 8$ 月 31 日 (小雨 $1.4 \mathrm{~mm}$ ) 雨中浓度变化起伏最小 $(2.91-$ $3.21 \mathrm{mg} / \mathrm{L})$ 。3 场降雨径流过程 DSi 浓度均低于同月的常规采样中 DSi 浓度 $5.57 \mathrm{mg} / \mathrm{L}$, 说明降雨起到了一定 的稀释作用,并且中雨的冲刷作用明显高于小雨。如图 4 所示, 3 场降雨的径流量变化特征, 8 月 25 日径流量 变化幅度较小, 仅在降雨初期有小峰值为 $13.34 \mathrm{~m}^{2} / \mathrm{h} ; 8$ 月 27 日中雨径流量略高于 8 月 25 日降雨中有明显的 峰值为 $14.49 \mathrm{~m}^{2} / \mathrm{h} ; 8$ 月 31 日径流量明显高于其他两场降雨, 可能由于多天连续降雨导致的, 峰值在降雨中 期为 $15.86 \mathrm{~m}^{2} / \mathrm{h} 。 3$ 场次降雨的径流量均呈现雨后径流量下降的规律, 说明地表水径流量受降雨过程的直接 影响。图 4 表明降雨-过程中 $\mathrm{pH}$ 值变化特征, 3 场次降雨过程 $\mathrm{pH}$ 值变化范围差异较小, 但 8 月 25 日 $\mathrm{pH}$ 值 偏高为 7.84-7.93。8 月 31 日 $\mathrm{pH}$ 值最低变化范围为 7.7-7.81。 $\mathrm{pH}$ 值变化规律与径流量呈现负相关, 说明 后寨河流域地表水 $\mathrm{pH}$ 值受降雨径流过程影响较大。

2.4 次降雨事件流域地下水径流 DSi 动态变化特征

图 5 为降雨径流过程中, 地下水 DSi 浓度、径流量及水体 $\mathrm{pH}$ 值变化。如图 5 所示, 3 场次降雨事件的降 雨径流过程 DSi 浓度起伏很小, 平均浓度分别为 $(5.75 \pm 0.12) \mathrm{mg} / \mathrm{L},(5.84 \pm 0.10) \mathrm{mg} / \mathrm{L}$ 及 $(5.73 \pm 0.09) \mathrm{mg} / \mathrm{L}$, 8 月 27 日中雨浓度略高一些。同月的常规采样中 DSi 浓度为 $5.87 \mathrm{mg} / \mathrm{L}$, 与降雨径流过程浓度差异不大, 说明 中小雨的降雨过程对地下水 DSi 浓度的影响较小。在图 5 中, 3 场降雨径流过程地下水径流量变化特征, 三 



图 4 降雨径流过程地表水 DSi 浓度变化

Fig.4 Variation of DSi concentration in surface water under rainfall-runoff process

场次降雨事件在降雨过程中径流量呈现平稳下降的趋势, 径流量最小为 8 月 25 日的 $(325.02 \pm 24.44) \mathrm{m}^{2} / \mathrm{h}$, 最 大值为 8 月 31 日的 $(481.63 \pm 17.51) \mathrm{m}^{2} / \mathrm{h}$, 由于多天连续降雨导致径流量明显高于其他两场降雨。三场次降 雨的地下水径流量变化规律与地表水相同 (图 4), 但起伏较小,地下水径流量变化相对稳定。如图 5 所示, 降 雨径流过程中 $\mathrm{pH}$ 值变化特征,三场次降雨过程 $\mathrm{pH}$ 值变化范围差异较小, 8 月 25 日 $\mathrm{pH}$ 值偏高为 7.86-7.97 略高于地表水。其他 2 场次降雨事件 $\mathrm{pH}$ 值仅在降雨初期有些起伏, 后期趋于稳定且 $\mathrm{pH}$ 值基本一致, 降雨径 流过程对地下水水体中 $\mathrm{pH}$ 值影响不明显。

\section{3 讨论}

\section{1 喀斯特流域硅酸盐岩的风化过程}

一般来说, 河流中地球化学循环过程中水化学成分主要受到自然过程的控制 (构造活动、化学风化过程、 生物及水文过程) 和人为活动的影响, 在这些过程当中, 岩石的风化作用是河流水化学的主要来源 ${ }^{[12]}$ 。喀斯 特地区的岩石风化作用主要分为碳酸盐岩风化, 硅酸盐岩风化及蒸发岩风化 ${ }^{[4]}$ 。如图 6 所示, 阳离子 $\left(\mathrm{Ca}^{2+}\right.$ $\left.\mathrm{Mg}^{2+}-\mathrm{Na}^{+}+\mathrm{K}^{+}\right)$和阴离子 $\left(\mathrm{HCO}_{3}^{-}-\mathrm{Si}_{-}-\mathrm{Cl}^{-}+\mathrm{SO}_{4}^{2-}\right)$ 三角图区分不同风化源区的物质组成。在阳离子三角图中, 旱 季与雨季河水离子组成基本相同, 均为明显富集 $\mathrm{Ca}^{2+}, \mathrm{Mg}^{2+}, \mathrm{Na}^{+}+\mathrm{K}^{+}$较低; 结合阴离子三角图, $\mathrm{Cl}^{-}+\mathrm{SO}_{4}^{2-}$ 含量 很高, $\mathrm{HCO}_{3}^{-}$次之, $\mathrm{Si}$ 含量最低。在阳离子中 $\mathrm{DSi}$ 与 $\mathrm{Na}^{+}$的相关性在旱季 $\left(1-4\right.$ 月), $\mathrm{Si}$ 与 $\mathrm{Ca}^{2+} 、 \mathrm{Na}^{+} 、 \mathrm{DIC}$ 及 $\mathrm{SO}_{4}^{2-}$ 无相关性 $\left(R^{2}<0.1\right)$, 说明河水中受蒸发岩风化作用影响强烈。在雨季, $\mathrm{Si}$ 与 $\mathrm{Ca}^{2+}$ 相关性最大 $\left(R^{2}=0.48\right)$ 及 DIC 的相关性较小 $\left(R^{2}=0.23\right)$, 经过雨季后的旱季 (9-12 月) $\mathrm{Si}$ 与 $\mathrm{Ca}^{2+}$ 及 DIC 的相关性相似, $R^{2}$ 分别为 0.44 及 0.35 , 与喀斯特流域的碳酸岩盐地质环境有直接的关系。结合阴、阳离子图可知, 后寨河流域水体为重 碳酸-钻型, 主要受到碳酸盐岩及蒸发岩控制。

水体中的 $\mathrm{Si}$ 主要受硅酸盐矿物溶解及铝硅酸盐矿物的水解。径流对于硅酸岩风化速率有着强有力的控 制作用 ${ }^{[21]}$, 水体中 $\mathrm{Na}^{+}+\mathrm{K}^{+}$主要来自于硅酸岩风化, 但水体中的部分 $\mathrm{Na}^{+}$离子又与 $\mathrm{Cl}^{-}$来自蒸发岩风化过程, 


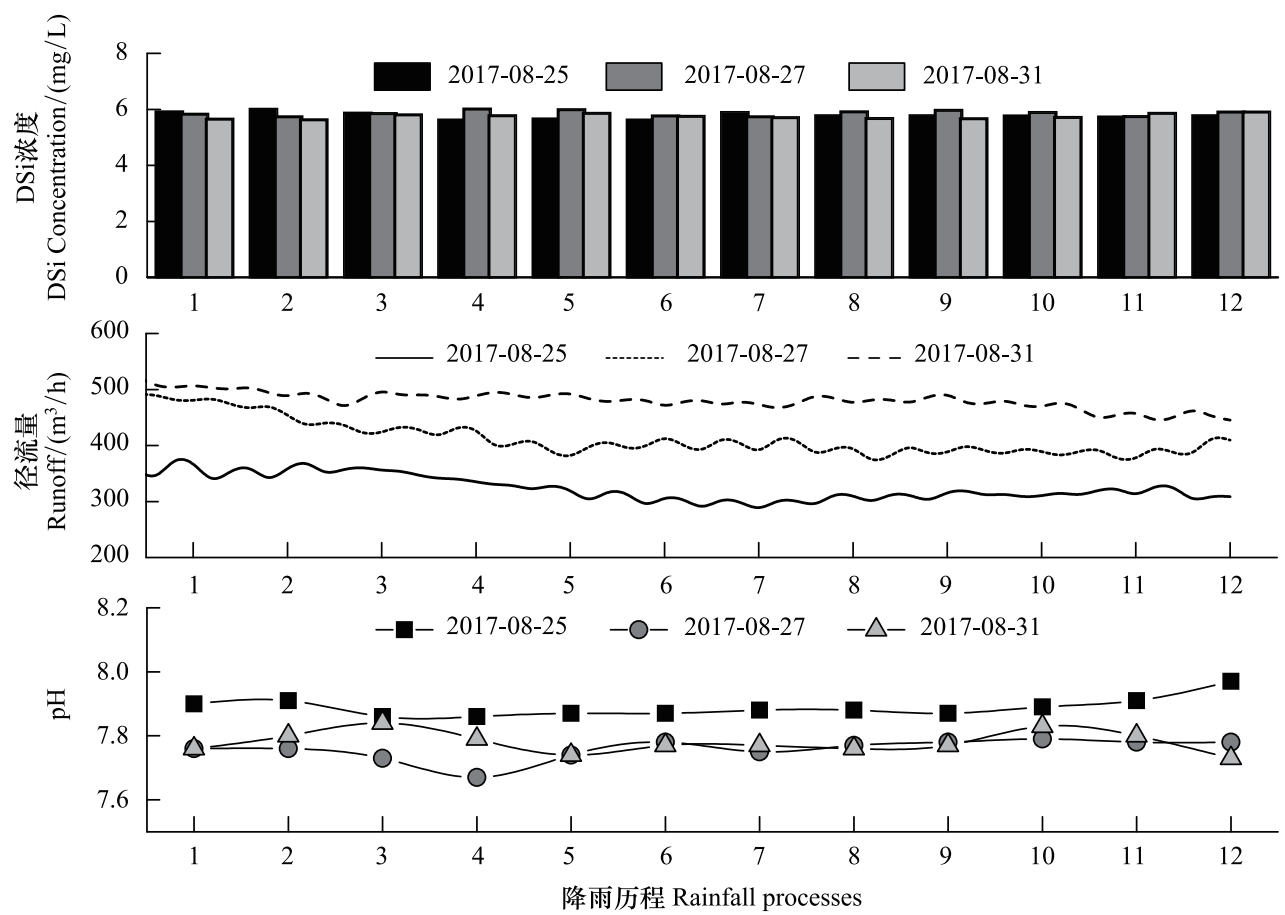

图 5 降雨径流过程地下水 DSi 浓度变化

Fig.5 Variation of DSi concentration in groundwater under rainfall-runoff process

故排除蒸发岩风化的影响, $\mathrm{DSi} /\left(\mathrm{Na}^{+*}+\mathrm{K}^{+}\right)$的比值可以反应硅酸岩风化程度 ${ }^{[22-23]}$ 。本研究区在旱季 $(1-4$ 月) $\mathrm{DSi} /\left(\mathrm{Na}^{+*}+\mathrm{K}^{+}\right)$的比值约为 1.07 , 雨季 $\mathrm{DSi} /\left(\mathrm{Na}^{+*}+\mathrm{K}^{+}\right)$为 1.56 , 旱季 $(9-12$ 月) 比值为 0.58 。本研究 $\mathrm{DSi} /\left(\mathrm{Na}^{+*}+\mathrm{K}^{+}\right)$的比值较低, 当比值 $<1$ 时说明该流域硅酸盐岩风化过程不强烈 ${ }^{[21]}$, 仅雨季硅酸盐风化作用 稍明显, 故后寨喀斯特流域水体中 DSi 浓度 $(72 \pm 26) \mu \mathrm{mol} / \mathrm{L}$ 明显低于全球河流 DSi 含量 $(133.02 \mu \mathrm{mol} / \mathrm{L})$ 及 全球湖泊及水库 DSi 浓度 $(122.13 \mu \mathrm{mol} / \mathrm{L})^{[22,24-25]}$ 。
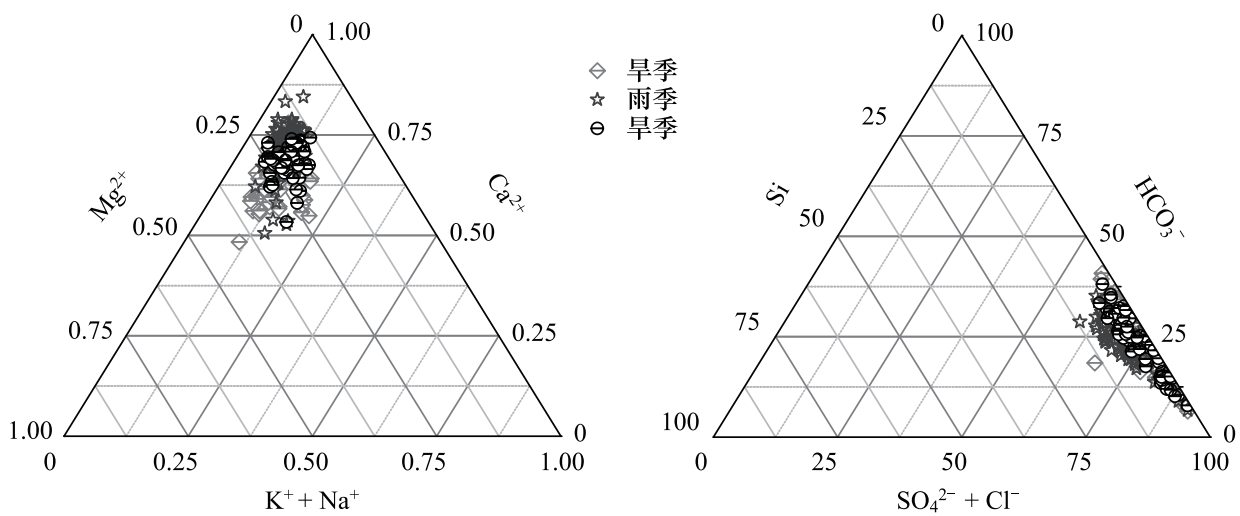

图 6 旱、雨季交替下后寨河流域水体水化学阳离子、阴离子三角分析图

Fig.6 The Ternary diagram of cationic and anion in the dry and wet seasons in Houzhai river basin

3.2 旱雨季交替下流域水体 DSi 通量收支特征

硅酸盐岩溶解及含硅土壤流失通过逐级河流输送 DSi 人海提供浮游植物的必要营养 ${ }^{[26]}$ 。DSi 迁移是流 域生态系统硅循环的重要过程, 在本研究后寨河流域溶解硅通量及迁移情况如图 7 所示, 2017 年全年 DSi 沉 降通量为 $4.52 \mathrm{~kg} / \mathrm{hm}^{2}$, 其中 8 月份沉降通量为最大值 $1.16 \mathrm{~kg} / \mathrm{hm}^{2}$ 。后寨河流域面积为 $80.65 \mathrm{~km}^{2}$, 故 2017 年 
DSi 湿沉降负荷为 $36.45 \mathrm{t} / \mathrm{a}$ 。后寨河流域出口处地表水 DSi 输出负荷为 $49.70 \mathrm{t} / \mathrm{a}$, 地下水的 DSi 输出负荷为 $161.69 \mathrm{t} / \mathrm{a}$, 是地表水的 3.25 倍。后寨河流域地处亚热带季风气候, 旱雨季差异明显, 雨季 DSi 湿沉降负荷为 $25.32 \mathrm{t}$ 占全年的 $69.5 \%$ 。流域地表水 DSi 迁移受到降雨过程的驱动影响十分显著 ${ }^{[27]}$, 呈现明显的正相关关 系 $\left(R^{2}=0.76\right)$, 雨季输出量为 $48.75 \mathrm{t} / \mathrm{a}$ 占全年输出负荷的 $98.1 \%$ 。地下水径流量与降雨量也呈现一定的正相 关 $\left(R^{2}=0.43\right)$, 由于降雨一地表水一地下水补给关系复杂, 故仅与降水的相关性不高, 但雨季输出量为 $83.15 \mathrm{t} / \mathrm{a}$ 占全年输出负荷的 $51.4 \%$ 。后寨河流域为下级水系输送的 DSi 总负荷为 $211.39 \mathrm{t} / \mathrm{a}$ 。与受硅酸盐岩控制的流 域相比, 九龙江北溪和西溪两大干流的年均向海输送 DSi 通量分别为 $59.3 \mathrm{~kg} / \mathrm{hm}{ }^{2} 、 95.0 \mathrm{~kg} / \mathrm{hm}^{2[28]}$, 是后寨河 流域的 $26.2 \mathrm{~kg} / \mathrm{hm}^{2}$ 的 2 倍和 3 倍。

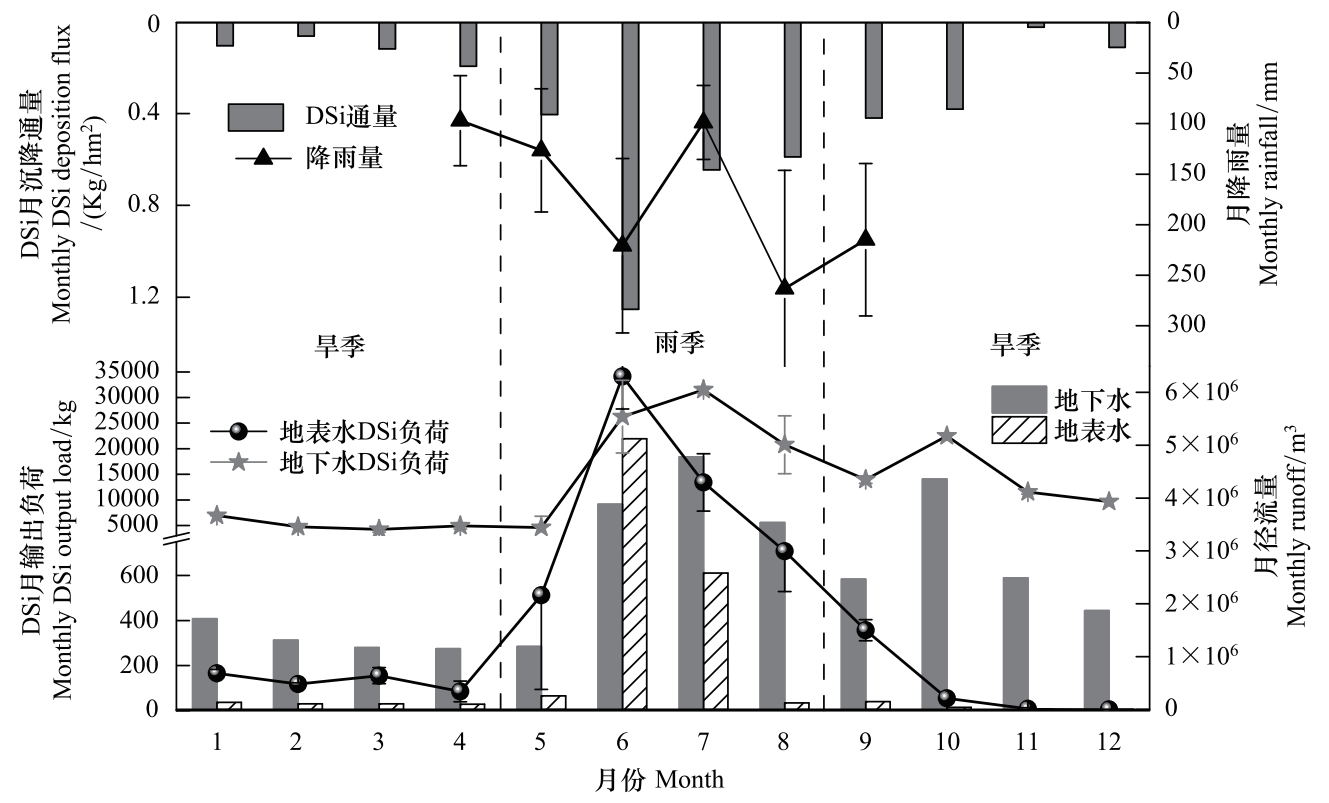

图 7 旱、雨季交替下后寨河流域降雨量、径流量、DSi 沉降通量及输出负荷变化特征

Fig.7 The variation characteristics of rainfall, discharge, DSi deposition flux and export load in the dry and wet seasons in Houzhai river basin

\section{3 旱雨季交替下流域水体 DSi 动态变化引起的环境效应}

河流 DSi 不仅受到流域岩石风化过程的影响,也受到人为活动的干扰。流域内长期的农业生产活动及土 地利用变化共同影响水体 DSi 含量。后寨河流经青山水库后经过 3 号采样点, 从图 3 可知 DSi 浓度明显下降 旱季 (1-4 月) 浓度下降 $29.0 \%$ 、雨季下降 $70.9 \%$ 。水体经过湖泊或水库, 流速减缓, 水体中 DSi 是通过生物利 用转化为无定形的生物硅 $(\mathrm{BSi})$ 。水库中硅藻吸收利用也是导致 DSi 浓度下降的原因 ${ }^{[29]}$ 。研究表明: 河流 DSi 浓度随着水库面积百分比的增加而降低, 主要是由水流停留时间增长导致的, 在低流速下 DSi 浓度下降 明显, 由于水更清澈, 硅藻的光合作用限制小, 生长不受影响, 吸收利用 DSi 效率较高 ${ }^{[26]}$ 。在旱季较低的流量 条件下, DSi 浓度和通量较低, 水体停留时间增长提高了 DSi 在水库中生物利用度, 导致下游河道的 DSi 浓度 明显下降。由于喀斯特流域是以碳酸盐岩溶解为主导的河流, 水体 DIC 浓度远高于 DSi 浓度, 故 DSi 浓度是 硅藻生长的主要限制因子。在旱雨季交替下, 河流 DSi 浓度差异性较大, 硅藻生长受到限制, 藻类群落结构发 生改变, 可能会改变河流中的营养成分并影响初级生产力, 甚至可能会改变后寨河流域浮游植物群的营养供 应 $^{[30-31]}$, 引发水质问题。对于流域水体营养物质供应的问题还需对农业活动及土地利用方式的影响开展长 期研究, 从长远的角度来预测浮游植物群落随着 DSi 浓度的动态变化后的改变。在未来的研究中, 除 DSi 外, 还应增加对 BSi 的监测来进一步研究陆地生态系统的硅循环过程和相关的环境效应。 


\section{4 结论}

(1) 亚热带季风气候的喀斯特流域 DSi 湿沉降浓度变化与降雨量变化有密切的关系, 小雨 DSi 平均浓度 为 $0.78 \mathrm{mg} / \mathrm{L}$, 暴雨 $\mathrm{DSi}$ 平均浓度为 $0.34 \mathrm{mg} / \mathrm{L}$ 。河流中 $\mathrm{DSi}$ 浓度变化雨季较高, 旱季较低, 说明降雨过程中对 土壤淋溶作用影响强烈,并且在地表水和地下水迅速交换过程中导致 DSi 浓度升高明显。另外,地表水径流 量及 DSi 浓度对降雨径流过程的响应比地下水明显。

(2) 后寨河流域 DSi 沉降通量及输出通量呈明显的旱、雨季差异。2017 年全年 DSi 沉降通量为 $4.52 \mathrm{~kg} /$ $\mathrm{hm}^{2}, \mathrm{DSi}$ 湿沉降负荷为 $36.45 \mathrm{t} / \mathrm{a}$, 雨季 DSi 湿沉降负荷为 $25.32 \mathrm{t}$ 占全年的 $69.5 \%$ 。流域河流 DSi 输出负荷受 到降雨过程的驱动影响显著, 地表水雨季输出量为 $48.75 \mathrm{t} / \mathrm{a}$ 占全年输出负荷的 $98.1 \%$,地下水雨季输出量为 $83.15 \mathrm{t} / \mathrm{a}$ 占全年输出负荷的 $51.4 \%$ 。

(3) 后寨河流域水体为重碳酸-钲型,主要受到碳酸盐岩及蒸发岩控制。流域硅酸盐岩风化过程不强烈, 仅雨季稍明显。后寨喀斯特流域水体中 DSi 浓度 $(72 \pm 26) \mu \mathrm{mol} / \mathrm{L}$ 明显低于全球河流 DSi 含量 ( $133.02 \mu \mathrm{mol} /$ L)。流域 DSi 浓度受人为水库影响明显, 旱季 (1-4 月) 浓度下降 $29.0 \%$ 、雨季下降 $70.9 \%$,旱雨季交替下， DSi 浓度差异性较大,藻类群落结构易发生改变,引发水质问题。

\section{参考文献 (References) :}

[ 1 ] Song X W, Gao Y, Green S M, Wen X F, Dungait J A J, Xiong B L, Quine T A, He N P. Rainfall driven transport of carbon and nitrogen along karst slopes and associative interaction characteristic. Journal of Hydrology, 2019, 573: 246- 254.

[ 2 ] Song X, Gao Y, Wen X F, Guo D L, Yu G R, He N P, Zhang J Z. Carbon sequestration potential and its eco-service function in the karst area, China. Journal of Geographical Sciences, 2017, 27(8): 967-980.

[ 3 ] 曹弘, 补建伟, 潘钊, 常启昕, 刘彦广. 黑河上游红泥沟小流域基于溶解硅的降雨径流路径示踪. 地质科技情报, 2018, 37(4): 219-224.

[ 4 ] Hao Z, Gao Y, Sun X M, Green S M, Wang J, Song X W, Dungait J A J, Johnes P J, Xiong B L, Quine T A, Sun X M, Wen X F, He N P. Using $\delta^{13} \mathrm{C}$ to reveal the importance of different water transport pathways in two nested karst basins, Southwest China. Journal of Hydrology, 2019, 571: 425-436.

[ 5 ] Hao Z, Gao Y, Sun X M, Wen X F, Xiong B L. Determining nitrogen and carbon footprints to reveal regional gross primary productivity and differentiation characteristics in karst and non-karst watersheds, China. Journal of Cleaner Production, 2019, 227: 1149-1160.

[ 6 ] 熊佰炼, 张进忠, 彭蹈, 宋贤威. 喀斯特红壤盐基离子及硅铝铁随径流流失研究. 水土保持研究, 2018, 25(3): 68-74.

[ 7 ] Carey J. Soil age alters the global silicon cycle. Science, 2020, 369(6508) : 1161-1162.

[ 8 ] de Tombeur F, Turner B L, Laliberte E, Lambers H, Mahy G, Faucon M P, Zemunik G, Cornelis J T. Plants sustain the terrestrial silicon cycle during ecosystem retrogression. Science, 2020, 369(6508): 1245-1248.

[ 9 ] Quigley K M, Griffith D M, Donati G L, Anderson T M. Soil nutrients and precipitation are major drivers of global patterns of grass leaf silicification. Ecology, 2020, 101(6) : e03006.

[10] Conley D J, Carey J C. Silica cycling over geologic time. Nature Geoscience, 2015, 8(6) : 431-432.

[11] 张乾柱, 陶贞, 高全洲, 马赞文. 河流溶解硅的生物地球化学循环研究综述. 地球科学进展, 2015, 30(1): 50-59.

[ 12] Deng H J, Tao Z, Gao Q Z, Yao L, Feng Y, Li Y H, Ding J, Wang Z G, Lyu X, Xu P. Variation of biogeochemical cycle of riverine dissolved inorganic carbon and silicon with the cascade damming. Environmental Science and Pollution Research, 2020, 27(23) : 28840-28852.

[13] Moosdorf N, Hartmann J, Lauerwald R. Changes in dissolved silica mobilization into river systems draining North America until the period 2081 2100. Journal of Geochemical Exploration, 2011, 110(1) : 31-39.

[14] Dürr H H, Meybeck M, Hartmann J, Laruelle G G, Roubeix V. Global spatial distribution of natural riverine silica inputs to the coastal zone. Biogeosciences, 2011, 8(3): 597-620.

［15］刘明, 支崇远, 李凯. 河流输送硅通量降低的机制及生态效应. 生态科学, 2010, 29(2): 171-175.

[16] 郭琴, 龙健, 廖洪凯, 李娟, 刘灵飞, 卢怡, 姚斌. 贵州高原喀斯特流域浅层地下水化学特征及质量评价一一普定后寨河为例. 环境化 学, 2017, 36(4): 858-866.

[17] Yue F J, Waldron S, Li S L, Wang Z J, Zeng J, Xu S, Zhang Z C, Oliver D M. Land use interacts with changes in catchment hydrology to generate chronic nitrate pollution in karst waters and strong seasonality in excess nitrate export. Science of the Total Environment, 2019, 696: 134062 . 
[18] 郝卓, 高扬, 张进忠, 徐亚娟, 于贵瑞. 南方红壤区氮湿沉降特征及其对流域氮输出的影响. 环境科学, 2015, 36(5): 1630-1638.

[19］马明真, 高扬, 郝卓. 亚热带典型流域 C、N 沉降季节变化特征及其耦合输出过程. 生态学报, 2019, 39(2): 599-610.

[20] 陆瑶, 高扬, 贾珺杰, 宋贤威, 陈世博, 马明真, 郝卓. 鄱阳湖流域多尺度 $\mathrm{C} 、 \mathrm{~N}$ 输送通量及其水质参数变化特征. 环境科学, 2019,40 (6) : 2696-2704

[21] $\mathrm{Wu} \mathrm{W} \mathrm{H,} \mathrm{Xu} \mathrm{S} \mathrm{J,} \mathrm{Yang} \mathrm{J} \mathrm{D,} \mathrm{Yin} \mathrm{H} \mathrm{W.} \mathrm{Silicate} \mathrm{weathering} \mathrm{and} \mathrm{CO}_{2}$ consumption deduced from the seven Chinese rivers originating in the QinghaiTibet Plateau. Chemical Geology, 2008, 249(3/4) : 307-320.

[22] Gaillardet J, Dupré B, Louvat $\mathrm{P}$, Allègre $\mathrm{C}$ J. Global silicate weathering and $\mathrm{CO}_{2}$ consumption rates deduced from the chemistry of large rivers. Chemical Geology, 1999, 159(1/4): 3-30.

[23] 孙明照. 硅酸盐风化速率及其控制因素: 来自不同"小流域系统" 的研究 [D]. 南京: 南京大学, 2018.

[24] Li S Y, Ye C, Zhang Q F. 11-Year change in water chemistry of large freshwater Reservoir Danjiangkou, China. Journal of Hydrology, 2017, 551: 508-517.

[25] Zhang Q Z, Tao Z, Ma Z W, Tang W K, Gao Q Z, Xu P, Lin Y W. Riverine hydrochemistry and $\mathrm{CO}_{2}$ consumption in the tropic monsoon region: a case study in a granite-hosted basin, Hainan Island, China. Environmental Earth Sciences, 2016, 75(5) : 436.

[26] Chen N W, Wu Y Q, Wu J Z, Yan X L, Hong H S. Natural and human influences on dissolved silica export from watershed to coast in Southeast China. Journal of Geophysical Research-Biogeosciences, 2014, 119(1) : 95-109.

[27] Hu Z Y, Wang G X, Sun X Y. Precipitation and air temperature control the variations of dissolved organic matter along an altitudinal forest gradient, Gongga Mountains, China. Environmental Science and Pollution Research, 2017, 24(11): 10391-10400.

[28] Lauerwald R, Hartmann J, Moosdorf N, Dürr H H, Kempe S. Retention of dissolved silica within the fluvial system of the conterminous USA. Biogeochemistry, 2013, 112(1/3): 637-659.

[29］陈能汪. 全球变化下九龙江河流-河口系统营养盐循环过程、通量与效应. 海洋地质与第四纪地质, 2018, 38(1): 23-31.

[30] 魏榆, 杨昌平, 晏浩, 刘再华. 喀斯特水库碳、硅耦合循环: 以红枫湖、普定水库和平寨水库为例. 地球与环境, 2020, 48(1): 1-9.

[31] 张乐辰, 陈喜, 张志才, 丁贤荣, 蒋瑞, 陈䂀. 喀斯特流域水化学特征及水-岩作用分析一一以后寨河流域为例. 地球与环境, 2018,46 (2) : 114- 120 . 